\title{
A study on the Dynamic Capabilities in Higher Education Institutions $\sim$ Examination on the variation of business organizations from educational settings
}

\author{
Mingchang Wu \\ National Yunlin University of Science and Technology \\ Department of Graduate school of Vocational and Technology Education \\ 123, University Rd. Sec. 3, Douliu, Yunlin 64002, Taiwn, \\ Wumc@yuntech.edu.tw \\ Wenlung Chang \\ National Yunlin University of Science and Technology \\ Department of Graduate school of Vocational and Technology Education \\ uenlung@chsc.tw \\ (*Correspondent author) \\ Hsiuhsu Lin \\ Chaoyang University of Technology \\ Department of Applied Foreign Languages \\ 168, Jifong E. Rd., Wufong Township, Taichung County 41349, Taiwan \\ hhlin@cyut.edu.tw \\ Yi-Hsueng Cheng \\ National Yunlin University of Science and Technology \\ Department of Graduate school of Vocational and Technology Education \\ D10043002@yuntech.edu.tw
}

\begin{abstract}
This study purported to explore the dynamic capabilities of facilitating educational improvement in Taiwanese universities of technology, and to further investigate the structural relationships among the five domains of dynamic capabilities. Research data were collected from a sample of 278 administrative personnel in universities of technology, and then analyzed undertaking Ridit Analysis Method, Confirmatory Factor Analysis (CFA), and Structural Equation Modeling (SEM). Based on conclusions, several concrete recommendations were finally provided for the educational improvement in universities of technology and future researches.
\end{abstract}

Keywords: universities of technology, dynamic capability, quality improvement

\section{Introduction}

The educational quality of universities of technology is a major concern of society and industries; universities of technology are therefore expected to effectively cultivate youngsters' professional talents to meet industrial demands with professional proficiencies. These concern and expectation have led to rapid expansion in terms of universities and student's enrollment over the recent more than a decade, but also created high competition pressure within the circle. The concern of these universities for their own educational improvement has been obviously transferred from static level to actually focusing on full-ranged and persistent dynamic level according to the changing world.

Dynamic capabilities are approved as the important factor which business organizations highly rely on for self-reviewing and persistently improving existing operational mechanisms in the face of environmental changes. ${ }^{31}$ Generally speaking, dynamic capabilities refer to the professional functions by which an organization itself takes the initiative in carrying out self-adjustment and self-improvement through analyzing the factors of competition and challenges while encountering both internal innovatory needs and external environment changes in order to improve the efficiency and to maintain its persistent growth of the 
organization itself. ${ }^{30}$ Therefore, the dynamic capabilities in business world usually include the responding mechanism for organization handling environmental changes ${ }^{1}$, the self-positioning mechanism for future development, ${ }^{25}$ the cultivating mechanism for organizational members enhancing better proficiency, ${ }^{12}$ the motivating mechanism for encouraging innovation, ${ }^{19}$ as well as the feedback mechanism for self-reviewing. ${ }^{11}$

What worth of thought-provoking is that, these five domains of dynamic capabilities are the strategies which have been always attached great importance and selfreinforced by business organizations, but whether today's universities of technology have also attached the same importance on them and put into practice? What kind of the structural relationships exist among these five domains?

\subsection{Research purpose}

The primary purpose of this study was consequently to investigate the dynamic capabilities which the universities of technology in Taiwan generally possessed, and to further scrutinize the internal structural relationships among the five domains of dynamic capabilities in the educational settings (Figure $1)$.

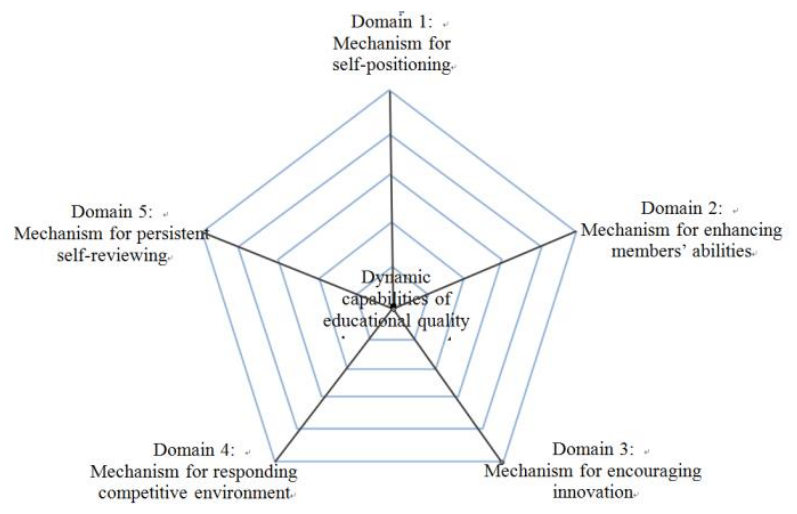

Fig.1.The five dynamic capability domains in universities of technology

\subsection{Research questions}

Based on the research purpose, this study focused on the following two research questions:

(1) How did universities of technology perform in dynamic capabilities of facilitating their educational improvement?

(2) How did the structural relationships exist among the five dynamic capability domains in the educational settings?

\section{Literature Review}

\subsection{The development and challenges of universities of technology in Taiwan}

Over the past decade, Taiwan has been experiencing rapt technology development and social changes like any other country in the world. The universities of technology in Taiwan therefore strived hard to upgrade facilities to prepare youngsters with competitive proficiency for their future careers successes. This movement also fostered these universities in Taiwan to greatly enhance in student enrollment. Many universities of technology had changed and upgraded their students' enrollment policies, resulting in the number of two-year technology colleges decreased from original 55 to present 26 , while the number of four-year universities of technology increased from original 15 to present 51 (Figure 2). ${ }^{20}$ This phenomenon revealed that, the universities of technology gradually undertook structural transformation in order to meet the changes in higher education market. ${ }^{15}$ It is worth noting that, this rapidly expanding phenomenon resulted in a series of subsequent pressures on these universities of technology, including the competition pressure among themselves and the self-positioning pressure of each university for its persistent development.

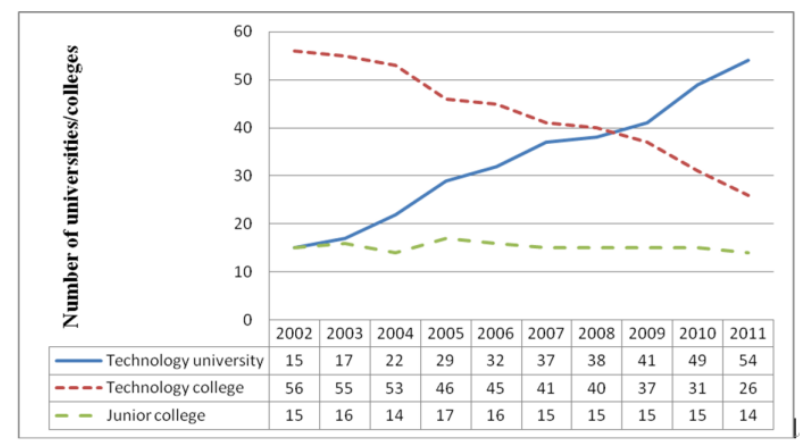

Fig.2.Quantitative statistics of universities of technology in 2002 2011 academic years (Source: Lee, 2012; compiled and plotted by this study)

Technology education has been preparing youngsters with employment competencies and always playing an important role for economical improvement and social development for a long time. ${ }^{22}$ This social expectation on educational qualities prompted the 
Taiwanese government to undertake a series of important policies in the past decade for the following objectives $^{26}$ : (1) to emphasize teaching quality; (2) to promote industry-academia cooperation; (3) to strengthen technology research and application; and (4) to carry out teaching integration and sharing mechanism. These motivating policies and corresponding strategies manifested the strong demands of government and general public on educational quality of universities of technology. ${ }^{22}$ Particularly, the enterprises required the teaching quality in universities of technology to mutually link with industries with advanced knowledge and skills according with industrial dynamic demands. Curiosity emerges that to what extent these universities of technology possess their dynamic capabilities while undertaking educational quality improvement.

\subsection{Dynamic capabilities}

\subsubsection{The definition of dynamic capabilities}

Dynamic capabilities are always the primary factor which business organizations highly rely on to ensure their policies responding internal and external changes in the competitive era. ${ }^{15}$ Dynamic capabilities are defined in various aspects: (1) Teece (1997) believes that dynamic capabilities are those abilities of a business organization to conduct resource integration, any reconfiguration, and strategy adjustment in response to rapid changes in the environment; (2) Eisenhardt and Martin (2000) proclaimed that dynamic capabilities are self-responding abilities of a business organization to integrate, reconfigure, gain, and release resources for grasping the pulse and trend of industry and social development in the course of emerging market opportunities, internal and external conflicts, and environmental turbulence; (3) Luo (2000) believes that dynamic capabilities are the dynamic abilities to create resources and improve internal performance and resource structure in order to maintain constant competitive advantages; and (4) Zollo and Winter (2002) believe that dynamic capabilities are created through organizational members' learning, and are continuing processes which cause the organization to integrate, construct, and reconfigure its own resources for rejuvenating functions.

Based on the aforementioned multifaceted definitions, dynamic capabilities are synthetically the abilities for business organizations themselves to carry out self-adjustment in response to internal needs and environmental changes, reform existing operational models and resource structure, and generate innovative developmental policies in order to improve the efficiency and competitiveness of the business organization. Through these persistent dynamic capabilities, business organizations can rectify and vividly utilize internal and external resources to create and maintain competitive advantages.

\subsubsection{Domain and contents of dynamic capabilities}

In a business organization, the dynamic capabilities are usually exerted to persistently search for better selfposition, improve operational processes, conduct reflective self-review for future development. ${ }^{31}$ That is to say, a business organization, while in exerting its dynamic capabilities, is first to analyze internal development directions and conditions, and then plan out business positioning and development path, and thereby to exert its dynamic capabilities through the mechanisms for persistent analyzing, positioning, and approach planning. ${ }^{25}$

In addition, the exertion of dynamic capabilities often depends on three important domains: capability possession, capability deployment, and capability upgrading. ${ }^{23}$ In the meantime, a business organization would generate innovative skills and create greater resources through constantly developing resources and enhancing organizational members' competencies. ${ }^{27,29}$

So it is obvious that, the dynamic capabilities of a business organization are the multifaceted dynamic selfreform abilities to autonomously cope with the fierce changes in external environment. ${ }^{33}$ Therefore, in the business world, responding or coping with changes in external environment should be the initiating factor of overall dynamic capabilities, and it causes itself to possess flexible responding abilities through important dynamic capability contents including cultivating the competencies of the organization's members and encouraging innovation. ${ }^{6}$

A series of studies comprehensively declared dynamic capabilities should contain five important domains:

A. Mechanism for responding competitive environment - The realization and ability of a business organization to analyze environmental threats, competitors' strengths and weaknesses, and take appropriate responding approaches when 
it senses being affected by environmental changes and fierce competitions. ${ }^{1}$ This is a key factor directly affecting the success or failure of a business organization. ${ }^{39}$

B. Mechanism for self-positioning - The ability of a business organization to comprehensively analyze its own advantageous and disadvantageous conditions, and visions, and thus appropriately position its stand point and goals for selfdevelopment. $^{25}$

C. Mechanism for enhancing members' abilities The mechanism for properly cultivating job competence of the organization's members based on its own innovatory development needs and visions. $^{12}$

D. Mechanism for encouraging innovation - The persistent development of a business organization relies on its innovative actions. This mechanism includes diverse domains such as institutional innovation, creation of operation model, and resource development and allocation innovation. ${ }^{19}$

E. Mechanism for persistently self-reviewing - In order to persistently self-review and immediately respond external challenges, the prompt reform and development of a business organization depend on an improvement mechanism based on visions and goals of self-development and internal and external environmental changes. ${ }^{29}$

\subsubsection{Research concept of dynamic capabilities in universities of technology}

Universities of technology are deliberately established to cultivate students with professional proficiency; the educational quality in these universities is tightly tied with social and industrial development pulses, and consequently appropriate self-positioning ${ }^{40}$ as well as professional competency enhancement for faculty members. $^{39}$ That is, the university mission and educational quality are dynamically revolutionizing in accordance with social changes and technology innovation. Universities of technology are therefore necessary to self-examine their own dynamic capabilities, particular, in the face of both the external challenges from over-expanded peer university numbers and rapid environmental changes, and the internal ones from faculty members' proficiency and student recruitment.
Of concern is how well the dynamic capabilities of current universities of technology in Taiwan realistically perform? In particular, whether these universities possess a complete set of persistent and autonomous reform approaches to their educational improvement? Therefore, this study emphasized on the five dynamic domains cited from business world, including "mechanism for self-positioning", "Mechanism for enhancing members' abilities", "mechanism for encouraging innovation", "mechanism for responding competitive environment", and "mechanism for persistently self-reviewing", these universities possessed. In the meantime, this study also explored whether some formats and extents of internal structural relationships existed among the five dynamic capability domains in the university settings.

\section{Research Methods}

This study took a questionnaire survey method to realize the dynamic capabilities existing in universities of technology and explore the structural relationships that may exist among the five dynamic capability domains.

\subsection{Research instruments}

The survey questionnaire used in this study was designed on the basis of the two existent instruments originally developed by Huang (2005) and Ma and Todorovic (2011). Huang's (2005) instrument titled as "Dynamic Capability Assessment for Vocational High School" was developed to assess the dynamic capabilities in vocational high schools and validated as reliable in overall assessment (Cronbach's $\alpha=0.97$ ) and 7 domains including Administration integration ( $\alpha$ $=0.92)$, Self-positioning $(\alpha=0.92), \quad$ Technology application $(\alpha=0.90)$, Organization learning ( $\alpha=0.89$ ), Innovation $(\alpha=0.90)$, Knowledge management $(\alpha=$ $0.81)$, and Strategy flexibility $(\alpha=0.75)$. Ma and Todorovic's (2011) instrument, focusing on university's connection with external resources and strategies responding external changes, was also validated in its four domains: Customer-oriented strategy $(\alpha=0.75)$. Competitor-oriented strategy $(\alpha=0.65)$, Internal crossdivision integration $(\alpha=0.71)$, and University performance $(\alpha=0.80)$. These two instruments, approved to be qualified instruments with acceptable reliabilities, almost delineated the major domains and contents of dynamic capabilities in educational settings. 
This study therefore adapted these two validated instruments considering the natures of dynamic capabilities, domains and question items used in the aforementioned two validated instruments, and educational missions and environmental characteristics of universities of technology, and finally modified them to be the "Dynamic Capability Instrument for Universities of technology". During the period of instrument development, the researchers invited five expert members with technical education backgrounds and questionnaire development experiences to validate the questionnaire items in order to ensure the instrument qualities. This final questionnaire consisted of five dynamic capability domains: mechanism for selfpositioning (7 questions), mechanism for enhancing members' abilities (7 questions), mechanism for encouraging innovation (6 questions), mechanism for responding competitive environment (8 questions), and mechanism for persistently self-reviewing ( 7 questions). The Five-point Likert's Scale was employed for data collection and statistical analysis (increased from " $1=$ strongly disagree" to " $5=$ strongly agree" ).

\subsection{Research population and sample}

The research major population is administrative personnel (including administrative faculty and staffs) of universities of technology in Taiwan; for the convenience and controllability of data collection, the administrative personnel in the 21 universities of technology located in the Central Region of Taiwan were selected as sample. These samples have participated in university administration for years and have policy-making experiences in their own university. Taking the opportunities of Central Region Universities of technology Meeting, the researchers asked this sample to fill up the questionnaires for the pilot study. A total of 145 questionnaires were collected; 120 of them valid $(83 \%)$ were used for pilot analysis to modify the questionnaire items for reliable and valid assessment in the main study.

After the pilot study analysis and consequent questionnaire modification, the amended formal questionnaires were mailed to sampled populations. The researchers received 278 completed and valid instruments returned from a total of 350 surveyed populations (response rate $79.4 \%$ ). These research populations consisted of administrative faculty members in public universities of technology $(\mathrm{N}=87,31.3 \%)$ and in private ones $(\mathrm{N}=191,68.7 \%)$ (Table 1). They had various experiences in school administration and policymaking participation.

Table 1. The research sample

\begin{tabular}{lcc}
\hline $\begin{array}{l}\text { Respondents' basic } \\
\text { information }\end{array}$ & $\begin{array}{c}\text { Number of } \\
\text { respondents } \\
(\mathrm{N}=278)\end{array}$ & $\begin{array}{c}\text { Percentage } \\
(\%)\end{array}$ \\
\hline $\begin{array}{l}\text { Nature of the university } \\
\quad \text { Public }\end{array}$ & 87 & $31.3 \%$ \\
$\quad$ Private & 191 & $68.7 \%$ \\
\hline Years of administration & & \\
$\quad$ Below 5 & 101 & $36.3 \%$ \\
6-10 & 49 & $17.6 \%$ \\
11-15 & 56 & $20.1 \%$ \\
$\quad$ Above 16 & 72 & $25.9 \%$ \\
\hline Position title & & \\
Administrative faculty & 198 & $71.2 \%$ \\
$\quad$ Administrative staff & 80 & $28.8 \%$ \\
\hline
\end{tabular}

\subsection{Pilot study}

This study undertook a pilot study with 120 samples in order to ensure the quality of the instrument.

\subsubsection{Validity analysis}

In order to ensure the construct validity of this questionnaire, the study carried out factor analysis on the collected 120 piloted questionnaires. The results indicated that the KMO value was 0.942 (higher than 0.9) (Table 2) and reached significant level justifying this instrument extremely suitable for conducting factor analysis. ${ }^{17}$ In addition, the extracted overall explanatory variance of five factors was $71.63 \%$, higher than the $70 \%$, approving the instrument with a good validity. That is, this instrument could effectively measure and explain theoretical concepts of dynamic capabilities. ${ }^{37}$

Table 2. Results of factor analysis

\begin{tabular}{llr}
\hline $\begin{array}{l}\text { KMO value (Kaiser-Meyer-Olkin Measure } \\
\text { of Sampling Adequacy.) }\end{array}$ & .942 \\
\hline & Approx. & 3818.32 \\
Bartlett's Test of Sphericity & Chi-Square & 595 \\
& Df & .000 \\
\hline & Sig. & $71.63 \%$ \\
\hline
\end{tabular}




\subsubsection{Reliability analysis}

The reliability analysis also resulted in the Cronbach's $\alpha$ for overall (.98) higher than 0.7and the Cronbach's $\alpha$ coefficients of all domains higher than 0.8 (see Table 3 ). These analytical data proved that this instrument possessed a high degree of consistency and reliability and could be used in this study. ${ }^{18}$

Table 3. Results of reliability analysis in pilot study

\begin{tabular}{lcc}
\hline \multicolumn{1}{c}{ Domain } & $\begin{array}{c}\text { Item } \\
\text { numbers }\end{array}$ & Cronbach's $\alpha$ \\
\hline $\begin{array}{l}\text { A. Mechanism for self- } \\
\text { positioning }\end{array}$ & $1 \sim 7$ & .94 \\
$\begin{array}{l}\text { B. Mechanism for enhancing } \\
\text { members' abilities }\end{array}$ & $8 \sim 14$ & .92 \\
$\begin{array}{l}\text { C. Mechanism for encouraging } \\
\text { innovation }\end{array}$ & $15 \sim 20$ & .89 \\
$\begin{array}{l}\text { D. Mechanism for responding } \\
\quad \text { competitive environment }\end{array}$ & $21 \sim 28$ & .94 \\
E. Mechanism for persistently & $29 \sim 35$ & .90 \\
$\quad \begin{array}{l}\text { self-reviewing } \\
\quad \text { Overall }\end{array}$ & & .98 \\
\hline
\end{tabular}

\subsection{Data analyses}

According with the research purposes, this study adopted the SPSS 18.0 and AMOS statistical analysis software to carry out the reliability and validity analyses, and descriptive statistics analyses. In addition, this study conducted the following two analyses:

(1) Ridit Analysis: Ridit scoring is generally used to compare two or more sets of ordered quantitative data; one set is designated as a reference (control group) against other sets which can be compared. ${ }^{10}$ This study employed the Ridit Analysis to explore the major factor with the foremost effect determined by the strength of each sequence level in ordinal scale with cumulative probability score for units corresponding specific distribution. ${ }^{4,10}$

(2) Structural Equation Modeling (SEM) analysis: The SEM analysis was undertaken to investigate the structural model of the five dynamic capability domains and the internal relationships among the content domains.

\section{Research Findings and Discussions}

\subsection{Reliability and validity analyses}

\subsubsection{Validity analysis}

In order to examine the validity of this measurement, this study carried out the principal components analysis and varimax. These analyses results revealed that the factor loading of each domain reached above 0.5 , and the cumulative explanatory variance reached $72.36 \%$ (Table 4). This instrument was therefore proved to possess a good validity. ${ }^{37}$

Table 4. Factor analysis results

\begin{tabular}{llr}
\hline $\begin{array}{l}\text { KMO value (Kaiser-Meyer-Olkin Measure } \\
\text { of Sampling Adequacy.) }\end{array}$ & .966 \\
\hline & Approx. & 8995.864 \\
& Chi-Square & 595 \\
Bartlett's Test of Sphericity & Df & .000 \\
& Sig. & $72.36 \%$ \\
\hline
\end{tabular}

\subsubsection{Reliability analysis}

The reliability of overall instrument reached .98 , and the reliabilities of the five domains were above .90 (Table 5). These results verified that the instrument had high and appropriate internal consistency and acceptable reliabilities.

Table 5. Reliability analysis results

\begin{tabular}{lcc}
\hline \multicolumn{1}{c}{ Dynamic capability domain } & $\begin{array}{c}\text { Test } \\
\text { Questions }\end{array}$ & Cronbach's $\alpha$ \\
\hline $\begin{array}{l}\text { A. Mechanism for self- } \\
\text { positioning }\end{array}$ & $1 \sim 7$ & .94 \\
$\begin{array}{l}\text { B. Mechanism for enhancing } \\
\quad \text { members' abilities }\end{array}$ & $8 \sim 14$ & .92 \\
$\begin{array}{l}\text { C. Mechanism for encouraging } \\
\quad \text { innovation }\end{array}$ & $15 \sim 20$ & .92 \\
$\begin{array}{l}\text { D. Mechanism for responding } \\
\quad \text { competitive environment }\end{array}$ & $21 \sim 28$ & .95 \\
E. Mechanism for persistently & $29 \sim 35$ & .92 \\
$\quad \begin{array}{l}\text { self-reviewing } \\
\quad \text { Over all }\end{array}$ & & .98 \\
\hline
\end{tabular}

These reliability and validity analysis results confirmed that the instrument could effectively measure the dynamic capability performance of this sample in universities of technology. 


\subsection{Dynamic capability performance in universities of technology}

The descriptive analysis revealed that the universities of technology in Taiwan generally recognized and possessed quite good dynamic capabilities (3.91) (Table 6 , Figure 3 ). The detailed analysis results further revealed that the mechanism for self-positioning was most dynamic capability domain (4.10); however, the mechanism for encouraging innovation was comparatively weak (3.72). That is, the universities of technology currently attached importance to dynamic capabilities of persistently ensuring educational quality, particularly emphasized on self-positioning for school development as well as enhancing faculty members' professional abilities. It could be a warning sign that the mechanism for encouraging innovation in universities of technology received relatively fewer attention and recognition. This innovation deficiency might inevitably cause a hysteresis in academic development and dull administration in these universities.

Table 6. Dynamic capabilities in universities of technology

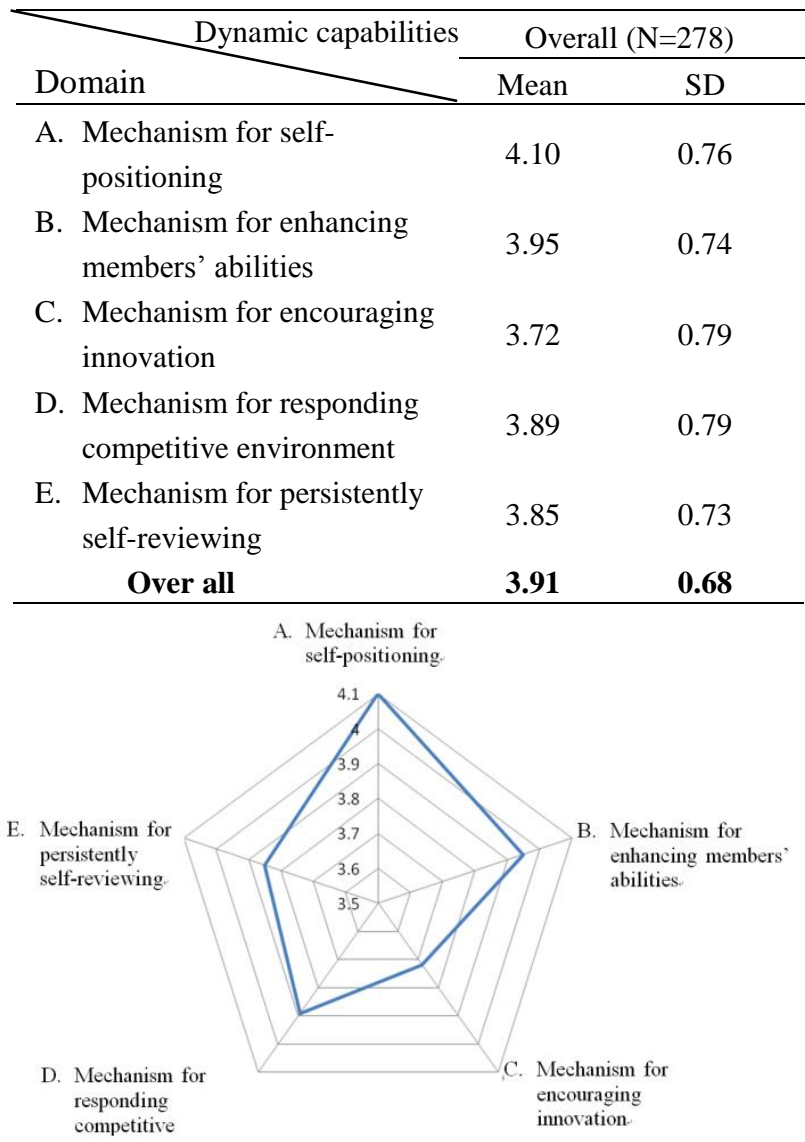

Fig.3.Radar chart of dynamic capabilities in universities of technology

\subsection{The structural model analyses of the dynamic capability domains}

According to Winter's study (2003), the dynamic capabilities of organizations in business world are generally initiated by the mechanism for responding external environmental competitions (D) which stimulates both the mechanisms for self-positioning (A) and for enhancing members' abilities (B). These two secondary mechanisms accordingly prompt the remaining two mechanisms for encouraging innovation (C) and for persistently self-reviewing (E) (Model 1, Figure 4). On the bases of this structural model in business worlds, the universities of technology activate dynamic capabilities starting from responding external environmental competitions, then trigger universities to prudently carry out self-positioning for university futures and subsequent educational improvement policies (Domain A), and to accordingly train their faculty members with required proficiency (B). Consequently, universities endeavor to encourage innovation on campuses (C) and undertake persistently self-reviewing (E) for long-termed dynamic improvement. However, it is worthy special attention, universities of technology in nature seem different from enterprises which are generally profit-oriented and administered by clear hierarchy authority. Universities of technology are academy-oriented organizations coadministered by faculty members with well-educated backgrounds and professional autonomy. University administration highly relies on in-group communication and collective decision-making. The structural model analysis is necessary to examine whether the dynamic capability model of business organizations is applicable to universities of technology employing the Confirmatory Factor Analysis (CFA).

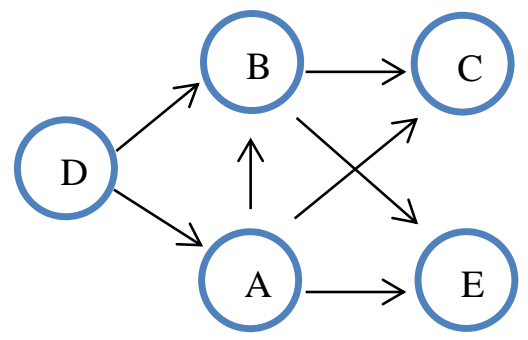

Fig.4. Model $1-$ The hypothetical structural model taking Mechanism for responding external environmental competitions (Domain D) as initiating point

Note: $\mathrm{A}-$ mechanism for self-positioning, $\mathrm{B}-$ mechanism for enhancing members' abilities, $\mathrm{C}-$ Mechanism for encouraging innovation, $\mathrm{D}-$ mechanism for responding competitive environment, $\mathrm{E}-$ mechanism for persistently self-reviewing 


\subsubsection{The confirmatory analysis results of measurement model 1}

The confirmatory analysis disclosed that, for all observed variables, the absolute values of skewness (1.24 to -0.47$)$ and kurtosis ( -0.41 to 0.83 ) were less than 2 (Table 7), the observatory coefficient of this model had a single variable normality. ${ }^{9}$ In addition, all standardized weighted coefficients ranged from 0.71 to 0.91 , less than 1 ; the standard error (SE) ranged from 0.12 to 0.23 in the appropriate standard error range; and the measured error variance $(\mathrm{EV})$ ranged between 0.14 to 0.43 , all positive. These results proved that this structural model did not violate the estimation problem and met the appropriate required range. ${ }^{16}$

Table 7. Confirmatory analysis results of measurement model (Model 1)

\begin{tabular}{ccccccccc}
\hline & SK & KU & SFL(t) & SE & SMC & EV & CR & AVE \\
\hline A & $-1.24 \sim$ & $0.11 \sim$ & $0.77^{*} \sim$ & $0.12 \sim$ & $0.59 \sim$ & $0.14 \sim$ & \multirow{2}{*}{0.93} & \multirow{2}{*}{0.70} \\
& -0.58 & 1.47 & $0.88^{*}$ & 0.14 & 0.77 & 0.38 & & \\
\hline B & $-0.88 \sim$ & $-0.01 \sim$ & $0.73^{*} \sim$ & $0.12 \sim$ & $0.53 \sim$ & $0.25 \sim$ & \multirow{2}{*}{0.91} & \multirow{2}{*}{0.62} \\
& -0.48 & 0.54 & $0.82^{*}$ & 0.14 & 0.66 & 0.34 & & \\
\hline C & $-0.61 \sim$ & $-0.41 \sim$ & $0.71^{*} \sim$ & $0.12 \sim$ & $0.50 \sim$ & $0.24 \sim$ & \multirow{2}{*}{0.92} & \multirow{2}{*}{0.65} \\
& -0.45 & 0.22 & $0.86^{*}$ & 0.16 & 0.75 & 0.43 & & \\
\hline D & $-0.95 \sim$ & $-0.15 \sim$ & $0.74^{*} \sim$ & $0.19 \sim$ & $0.55 \sim$ & $0.18 \sim$ & \multirow{2}{*}{0.93} & \multirow{2}{*}{0.69} \\
& -0.56 & 0.83 & $0.91^{*}$ & 0.23 & 0.83 & 0.37 & & \\
\hline E & $-0.83 \sim$ & $-0.02 \sim$ & $0.73^{*} \sim$ & $0.12 \sim$ & $0.53 \sim$ & $0.19 \sim$ & \multirow{2}{*}{0.90} & \multirow{2}{*}{0.60} \\
& -0.51 & 0.38 & $0.86^{*}$ & 0.14 & 0.74 & 0.36 & & \\
\hline
\end{tabular}

Note 1: * indicates reaching statistical significance level when $\alpha<0.05$.

Note 2: SK is skewness; $\mathrm{KU}$ is kurtosis; SFL(t) is standardized factor loading, $\mathrm{t}$ is $\mathrm{t}$-value; $\mathrm{SE}$ is standard error of the factor loading; SMC is squared value of multiple correlation; $\mathrm{EV}$ is error variance; $\mathrm{CR}$ is combined reliability; AVE is average variance extract amount.

However, further analysis results (Table 8) divulged that, almost all absolute fit indexes of this model did not comply with standard values; and all incremental fit indexes were also not consistent with standard values, revealing that the fitness of this model was not acceptable. Specifically speaking, universities of technology are different from business organizations in their dynamic capability structure, not initiated by responding external environmental competitions (Domain D). There should be another dominant factor which, in various structural model, instigates the dynamic capabilities of universities of technology.
Table 8 Overall model fit index for Model 1

\begin{tabular}{ccccc}
\hline \multicolumn{2}{c}{ Test statistic } & $\begin{array}{c}\text { Standard } \\
\text { value }\end{array}$ & Test result & $\begin{array}{c}\text { Model } \\
\text { fit }\end{array}$ \\
\hline \multirow{4}{*}{$\begin{array}{c}\text { Absolute fit } \\
\text { Index }\end{array}$} & GFI & $>0.90$ & 0.74 & No \\
& AGFI & $>0.90$ & 0.70 & No \\
& RMR & $<0.05$ & 0.05 & Yes \\
& RMSEA & $<0.08$ & 0.08 & No \\
\hline & NFI & $>0.90$ & 0.83 & No \\
& NNFI & $>0.90$ & 0.87 & No \\
Incremental & CFI & $>0.90$ & 0.88 & No \\
fit Index & RFI & $>0.90$ & 0.82 & No \\
& IFI & $>0.90$ & 0.88 & No \\
\hline Parsimonious & PGFI & $>0.05$ & 0.65 & Yes \\
fit Index & $\chi^{2} / d f$ & $\leqq 3$ & 2.91 & Yes \\
\hline
\end{tabular}

\subsubsection{The exploration of initiating dynamic capability domain - result of Ridit Analysis}

In order to explore the initiating domain of dynamic capabilities in universities of technology, this study conducted the Ridit Analysis Method. ${ }^{4}$ First, for $\mathrm{k}$ questions, the Ridit assessed the research objects' responses in $\mathrm{j}$ ordinal scale $(1,2 \ldots, \mathrm{j})$ using 5-point Likert's scale (5: very agree $\sim 1$ :very disagree) in this study. Then, the researchers took the cumulative probability score instead of the percentage in sequence to represent the strength of each sequence level in ordinal scale; i.e., calculated the mean according to answering frequency of each research object on different domains, ${ }^{34}$ to judge the strengths of the five dynamic capability domains and to identify the major factor among these five domains.

For this study, using the frequency of each sequence level in control group to multiply the corresponding Rvalue of standard group (Table 9), this study obtained the calculated results, as well as the upper limit value and lower limit value of the confidence interval for the five domains (Table 10). If the confidence intervals between two domains overlap, then those two domains have no difference, on the other hand, while no overlapping between two domains indicates significant difference exists. In addition, in terms of judging direction, the level ordering sequence of surveyed items in this study is downward; the smaller the obtained Ridit value represents the better the level of agree. ${ }^{7}$ The level of agree of the control group is better than the standard 
group while the $\mathrm{R}$ (control group) $<0.5$. The upper limit and lower limit values of each sequence level $\mathrm{R}$-value confidence interval of the control group for the five domains are plotted as shown in Figure 5.

Table 9 Importance analysis on dynamic capability domains R-value calculation for each sequence level of standard group

\begin{tabular}{|c|c|c|c|c|}
\hline Domain & Agree & $\begin{array}{c}\text { No } \\
\text { comment }\end{array}$ & Disagree & Total \\
\hline A (1) & 219.57 & 43.29 & 15.14 & 278 \\
\hline B (2) & 205.14 & 53.86 & 19 & 278 \\
\hline C (3) & 174.17 & 76.83 & 27 & 278 \\
\hline D (4) & 196.88 & 59.25 & 21.88 & 278 \\
\hline E (5) & 194.14 & 63.29 & 20.57 & 278 \\
\hline Total (6) & 989.90 & 296.51 & 103.59 & 1390 \\
\hline$(6) *(1 / 2) \quad(7)$ & 494.95 & 148.26 & 51.79 & \\
\hline $\begin{array}{c}\text { (6)Cumulative } \\
(8)\end{array}$ & & 989.90 & 1286.41 & \\
\hline$(7)+(8) \quad(9)$ & 494.95 & 1138.16 & 1338.21 & \\
\hline $\begin{array}{c}\mathrm{R}=(9) / 1390 \\
(10)\end{array}$ & 0.36 & 0.82 & 0.96 & \\
\hline
\end{tabular}

Table 10 Importance analysis table of dynamic capability domains - R-value calculation of each sequence level of control group of five domains

\begin{tabular}{ccccccc}
\hline Domain & Agree & $\begin{array}{c}\text { No } \\
\text { comment }\end{array}$ & $\begin{array}{c}\text { Disagre } \\
\mathrm{e}\end{array}$ & $\mathrm{R}$ & $\begin{array}{c}\text { Upper } \\
\text { limit }\end{array}$ & lower \\
limit
\end{tabular}

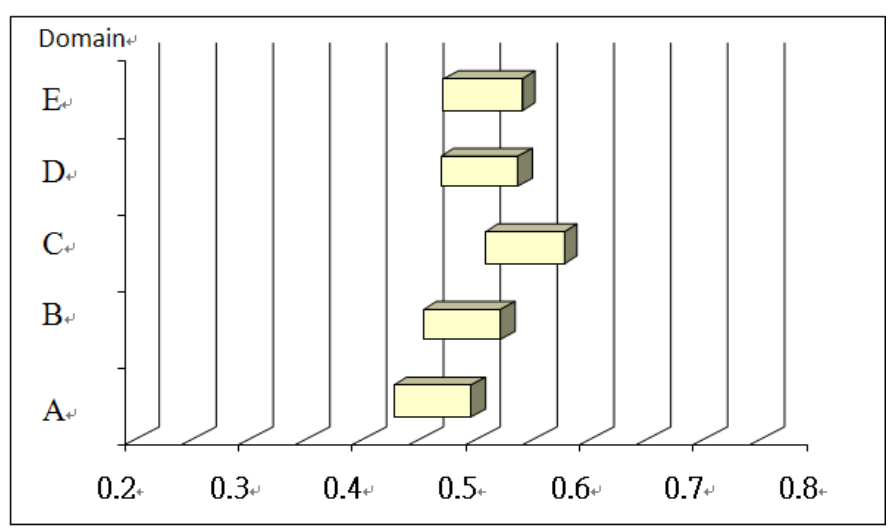

Fig.5. R value confidence interval diagram of each sequence level of control group for the five domains
This study took 0.5 as the center point for both the upper limit and lower limit values of sequence level $\mathrm{R}$ value confidence interval of these five domains (Figure 5); the farer to the left, the higher the degree of agreement, and the farer to the right, the lower the degree of agreement. The result revealed that the research participants most agreed with that the "mechanism for self-positioning" (Domain A) played a key role in the educational improvement, and it led the persistent development of overall dynamic capabilities. This study accordingly took this domain (A) as the initiating domain of dynamic capabilities and derived the hypothesis measurement Model 2. This result, just like Bingham's (1993) and Zott's (2003) studies, reveals that a technology university analyzes and identifies its own strengths and traits through an explicitly and clearly self-positioning to stimulate consequent dynamic capabilities for educational improvement (Model 2, Figure 6).

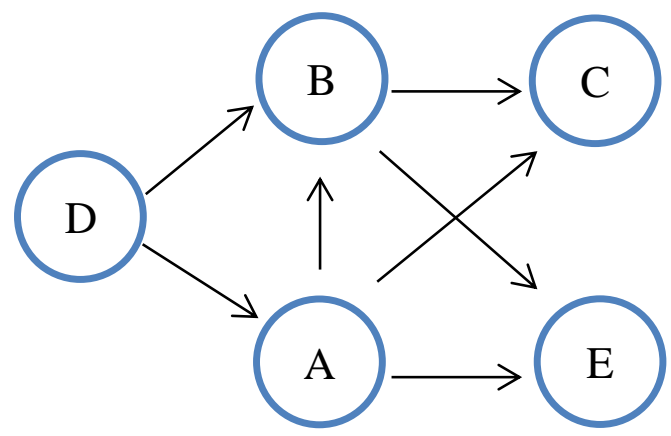

Fig.6.: Model 2-The measurement model using mechanism for self-positioning (Domain A) as initiating point

Note: $\mathrm{A}-$ mechanism for self-positioning, $\mathrm{B}-$ mechanism for enhancing members' abilities, $\mathrm{C}-$ Mechanism for encouraging innovation, $\mathrm{D}$-mechanism for responding competitive environment, $\mathrm{E}-$ mechanism for persistently self-reviewing

\subsubsection{The confirmatory analysis results of Model 2}

Based on the Ridit analysis result, this study consequently conducted the fitness analysis on the new model taking the mechanism for self-positioning (Domain A) as a leading domain. The analysis resulted in a significant $\chi^{2}$ value $(0.01$, less than 0.05$)$ (Table 11$)$. 
Table 11 Overall model fit index for Model 2

\begin{tabular}{ccccc}
\hline \multicolumn{2}{c}{ Test statistic } & $\begin{array}{c}\text { Standard } \\
\text { value }\end{array}$ & Test result & $\begin{array}{c}\text { Model } \\
\text { fit }\end{array}$ \\
\hline \multirow{4}{*}{$\begin{array}{c}\text { Absolute fit } \\
\text { Index }\end{array}$} & GFI & $>0.90$ & 0.91 & Yes \\
& AGFI & $>0.90$ & 0.90 & Yes \\
& RMR & $<0.05$ & 0.04 & Yes \\
& RMSEA & $<0.08$ & 0.08 & Yes \\
\hline & NFI & $>0.90$ & 0.91 & Yes \\
Incremental & NNFI & $>0.90$ & 0.90 & Yes \\
fit Index & CFI & $>0.90$ & 0.91 & Yes \\
& RFI & $>0.90$ & 0.83 & No \\
& IFI & $>0.90$ & 0.90 & Yes \\
\hline Parsimonious & PGFI & $>0.05$ & 0.66 & Yes \\
fit Index & $\chi^{2} / d f$ & $\leqq 3$ & 2.73 & Yes \\
\hline
\end{tabular}

However, because the chi-square test itself is vulnerable to the sample size, therefore, this study also used the ratio of chi-square test value and degree of freedom (i.e., normed chi-square) to replace the chisquare value to test the fitness of the model according to sample size. ${ }^{2}$ In addition, Gefen, Straub and Boudreau
(2000) suggested that the model has a better fitness while the GFI, NFI, NNFI, CFI, and AGFI indexes are greater than 0.90 . Overall speaking, all major indexes in the new model over reached the recommended standard values; that is, the overall fitness is within the acceptable range. This model, taking the mechanism of self-positioning as a leading dynamic capability domain, possesses a reasonably explanatory effectiveness and is justified as a acceptable model for universities of technology, different from that for enterprises.

\subsubsection{The analytical results of internal structural relationships among various domains of dynamic capabilities - Confirmatory analysis of model 2}

In order to further ensure the quality and consistency of this modified model initiated by the mechanism for selfpositioning, this study examined the structural relationships among the five dynamic capability domains within this newly hypothetical model. The examination on path-coefficients among the five domains obtained the crucial results indicating the $t$ values of all paths were over the standard value of 1.96. These $\mathrm{t}$ values approved the significant effects of all path coefficients (Table 12). ${ }^{8}$

Table 12 Effect analysis results of overall model 2

\begin{tabular}{|c|c|c|c|c|c|c|}
\hline Potential independent variable & $\begin{array}{l}\text { Potential dependent } \\
\text { variable }\end{array}$ & $\begin{array}{l}\text { Direct } \\
\text { effect }\end{array}$ & $\begin{array}{l}\text { Indirect } \\
\text { effect }\end{array}$ & $\begin{array}{l}\text { Overall } \\
\text { effect }\end{array}$ & $\mathrm{t}$ value & Hypothesis \\
\hline $\begin{array}{l}\text { A. Mechanism for self- } \\
\text { positioning }\end{array}$ & \multirow{2}{*}{$\begin{array}{l}\text { B. Mechanism for } \\
\text { enhancing members' } \\
\text { abilities }\end{array}$} & $0.44^{* *}$ & $\begin{array}{c}0.36 \\
(0.79 * 0.45) \\
\end{array}$ & 0.80 & 5.65 & Established \\
\hline $\begin{array}{l}\text { D. Mechanism for responding } \\
\text { competitive environment }\end{array}$ & & $0.45 * *$ & - & 0.45 & 5.67 & Established \\
\hline $\begin{array}{l}\text { A. Mechanism for self- } \\
\text { positioning }\end{array}$ & $\begin{array}{l}\text { D. Mechanism for } \\
\text { responding } \\
\text { competitive }\end{array}$ & $0.80 * * *$ & - & 0.80 & 11.31 & Established \\
\hline $\begin{array}{l}\text { B. Mechanism for enhancing } \\
\text { members' abilities }\end{array}$ & \multirow{2}{*}{$\begin{array}{l}\text { C. Mechanism for } \\
\text { encouraging } \\
\text { innovation }\end{array}$} & $0.57 * *$ & - & 0.57 & 6.82 & Established \\
\hline $\begin{array}{l}\text { D. Mechanism for responding } \\
\text { competitive environment }\end{array}$ & & $0.37 * *$ & - & 0.37 & 5.18 & Established \\
\hline $\begin{array}{l}\text { B. Mechanism for enhancing } \\
\text { members' abilities }\end{array}$ & \multirow{2}{*}{$\begin{array}{l}\text { E. Mechanism for } \\
\text { persistently self- } \\
\text { reviewing }\end{array}$} & $0.23 *$ & - & 0.23 & 3.43 & Established \\
\hline $\begin{array}{l}\text { D. Mechanism for responding } \\
\text { competitive environment }\end{array}$ & & $0.71 * *$ & - & 0.71 & 7.87 & Established \\
\hline
\end{tabular}

Note 1: $* \mathrm{P}<0.05, * * \mathrm{P}<0.01, * * * \mathrm{P}<0.001$ indicates reaching significant level

Note 2: “- " indicates no such effect 


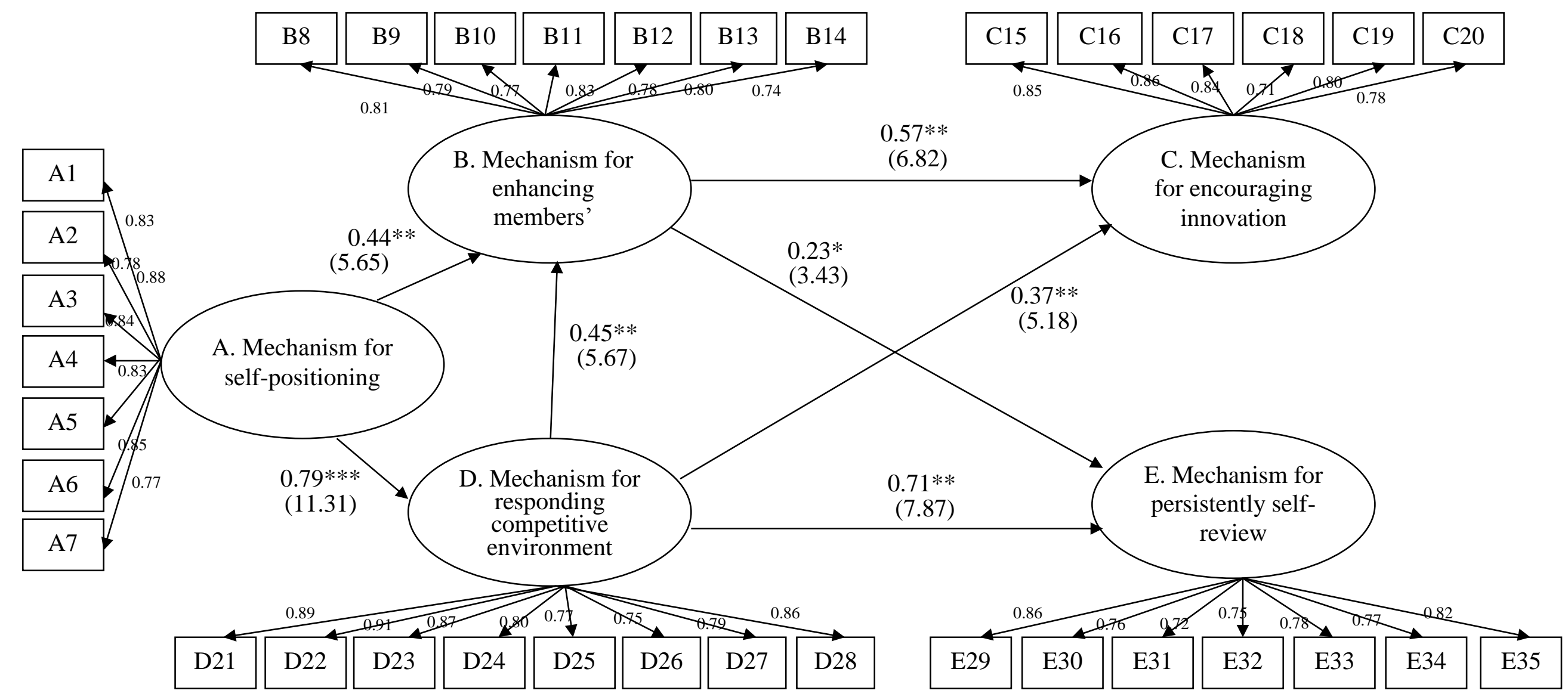

Figure 7: Relationship model path diagram of various domains of dynamic capabilities

Note 1: $\quad * \mathrm{P}<0.05, * * \mathrm{P}<0.01, * * * \mathrm{P}<0.001$ indicates reaching significant level

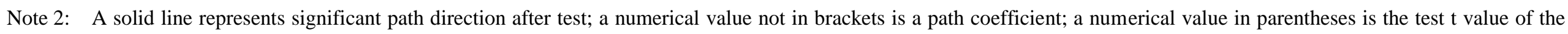
path coefficient parentheses test $t$ value of the path coefficients 
The results of SEM structural analysis revealed that there were significant structural relationships obviously existing among these five dynamic capability domains (Figure 7). These structural relationships justified that: (1) the internal "mechanism for self-positioning" in universities of technology is the primarily initiating domain of dynamic capabilities which triggers both "mechanism for enhancing members' abilities" (path coefficients .44, p<.01), and "mechanism for responding competitive environment" of these universities of technology (path coefficients .80, p<.001); (2) the "mechanism for responding competitive environment" accordingly drives with significance the "mechanism for enhancing members' abilities" (path coefficients .45, $\mathrm{p}<.01$ ), "mechanism for encouraging innovation" (path coefficient .39, $\mathrm{p}<.01$ ), and "mechanism for persistently self-reviewing" for these universities (path coefficient .71, p<.01); and (3) when an university is committed to the mechanism for enhancing members' professional abilities, it would, as a result, significantly affect various mechanisms for encouraging innovation (path coefficient .57, p<.01), and persistently selfreview the effectiveness of educational improvement (path coefficient .23, $\mathrm{p}<.05$ ). These significant structural relationships confirm that there are well-built interlocking relationships among the five dynamic capability domains which mutually lock and trigger every other, although each dynamic domain has its own independent and specific function.

\section{Conclusions and Recommendations}

\subsection{Conclusions}

This study purported to explore the educational improvement factors in universities of technology exploiting a dynamic capability perspective, as well as further investigate the internal structural relationships among these dynamic capability domains. According to the research results, the following conclusions were drawn.

(1) The universities of technology in Taiwan generally possess the acceptable level of dynamic capabilities for educational improvement, and become accountably prepared to meet the everlasting changes from both internal and external environments with sufficient competency.

Traditionally, the assessment on educational quality of universities mostly focuses on tangible academic achievements and assets, ${ }^{28}$ including campus size, facilities and equipments, faculty's performance, students' achievements, etc.; However, this tangible but static performance assessment can only reflect current state of the university achievements, and potentially ignore the dynamic mechanism and persistent development capabilities which are the dominant factor of universities' long-termed development. ${ }^{5}$

(2) The mechanism for encouraging innovation caught the weakest recognition compared with the other four domains; this surprising occurrence might represent that the habitual top-down administrative recognition still generally prevail on campuses and the innovation vitality could be limited.

It is worth special and reflective notes that the mechanism for encouraging innovation is proved as comparatively weak dynamic capability on campuses. This mechanism is crucial to encourage faculty even staff member at all positions to instigate creative strategies and policies for quality improvement. However, the weakness andlor ignorance of this encouraging innovation mechanism might restrain the kinetic energy and limit universities of technology to inherited regimes commanded by a top-down authoritarian leadership.

(3) The proactive mechanism for self-positioning, in university settings, is proved as the essential factor initiating dynamic capabilities for educational improvement in universities of technology.

This invigorating finding, resulted from the Ridit Analysis, seemed to be different from that of previous study regarding business organizations in which the dynamic capabilities were initiated from passive dynamic mechanism for responding external competitive environment. ${ }^{33}$ This differential initiating dynamic capability might result from that universities of technology are co-administrated by academic elites who specialize at actively analyzing the trend of social development for universities development; ${ }^{36}$ however, most of business organizations are guided by a single goal for administrative effectiveness and profit production.

(4) The high internal relationships, existed among the five domains of dynamic capabilities, suggested that this dynamic capability mechanism in university settings, even its sub-domain, could be led by a dynamic body; in addition, this phenomenon insinuated the quality improvement of these universities of technology rely on overall factors, as a whole, rather than any single one separately.

This study exposed significant relationships among the five dynamic capability domains and identified that these dynamic capabilities would mutually even interlockingly affect each other, although each domain has its own independent functions and can be cultivated alone. An university is just like a lively organism which, in the occasion of changing a domain or conducting a partial reform, would inevitably have a joint reaction on all remaining domains and levels. Any improvement reform of an university depends on holistic action of 
multiple domains rather than any single level or department.

\subsection{Recommendations}

In order to further promote the persistent educational improvement of universities of technology, this study, based on research findings and conclusions, finally proposed the following recommendations:

(1) The dynamic capabilities should be exerted in universities of technology, which are vivacious organisms for everlasting academic development and human resource cultivation, in order to persistently upgrade their educational missions and quality insurance through self-positioning, faculty member recruiting, innovation encouragement, and prompt self-improvement according with environmental changes.

(2) Administrators in leading positions are suggested to initiate quality improvement starting from aggressively autonomous self-positioning, various from that in business world starting from passively responding external competitions, for school goals and development policies.

(3) The dynamic capabilities possess high relationship among its five domains relying on and supporting any others; it suggests university leaders should have proficient skills to coordinate and integrate any endeavors from various departments for a single mission persistently improving educational quality with dynamics.

(4) This study purported to explore the dynamic capabilities and consequential issues existing in universities of technology employing the questionnaire survey method. Some inevitable limitations theoretically and practically exist in this self-rating quantitative research method; future studies are recommended to take qualitative research methods to in-depth interview senior administrative heads and on-site observe the decision-making processes in order to further understand the dynamic capabilities in universities of technology while planning educational improvement policies and encountering internal and external changes.

\section{References}

1. Augier, M., \& Teece, D. J. (2007). Dynamic capabilities and multinational enterprise: penrosean insights and omissions. Management International Review, 47(2), 175192.

2. Bagozzi, R. P., \& Yi, Y. (1988). On the evaluation of structural equation models. Academic of Marketing Science, 16(1), 74-94.
3. Bingham, F. G. (1993). Marketing the institution of higher learning: a research analysis enrollment model. Journal of Marketing for Higher Education, 4 (1), 59-72.

4. Bross, I. D. J. (1958). How to use ridit analysis. Biometrics, 14(1), 18-38.

5. Cavaljuga, S., \& Nikolic, A. (2009). Self-evaluation/selfassessment as part of quality culture in higher education An example of the faculty of medicine, university of Sarajevo. Technics Technologies Education Management, 4(1), 3-14.

6. Cepeda, G., \& Vera, D. (2007). Dynamic capabilities and operational capabilities: a knowledge management perspective. Journal of Business Research, 60, 426-437.

7. Chang, B.Y. \& Choa, T. M. (1998). Ridit Analysis. In Hou, S. L. Science Research and Statistics. Hunan: Hunan Science Technology Press.

8. Chiou, H. J. (2011). Structural Equation Modeling. Taipei: Yeh Yeh Book Gallery.

9. Curran, P. J., West, S. G., \& Finch, J. F. (1996). The robustness of test statistics to nonnormality and specification error in confirmatory factor analysis. Psychological Methods, 1(1), 16-29.

10. Donaldson, G. W. (1998). "Ridit scores for analysis and interpretation of ordinal pain data". European Journal of Pain, 2 (3): 221-227.

11. Easterby-Smith, M., \& Prieto, I. M. (2008). Dynamic capabilities and knowledge management: an integrative role for learning? British Journal of Management, 19, 235-249.

12. Eisenhardt, K. M., \& Martin, J. A. (2000). Dynamic capabilities: what are they? Strategic Management Journal, 21, 1105-1121.

13. Gefen, D., Straub, D. W., \& Boudreau, M. C. (2000). Structural equation modeling and regression: Guidelines for research practice. Communications of the Association for Information Systems, 4, 2-77.

14. Hair, J. F. Jr., Black, W. C., Babin, B. J., Anderson, R. E., $\&$ Tatham, R. L. (2006). Multivariate data analysis $\left(6^{\text {th }}\right.$ ed.). Upper Saddle River, NJ: Prentice-Hall.

15. Huang Z. Y. (2005). Development and Validation of Dynamic Capability Index for School Administration (unpublished Dissertation). National Chengchi University. Taipei.

16. Jöreskog, K. G., \& Sörbom, D. (1984). LISREL VI: User guide ( $3^{\text {rd }}$ ed.). US: Scientific Software International, Inc.

17. Kaiser, H. F. (1974). Little Jiffy, Mark IV. Journal of Educational and Psychological Measurement, 34(1), 111117.

18. Kerlinger, F. N. (1986). Foundations of behavioral research ( $3^{\text {rd }}$ ed.). New York: Holt, Rinehart and Winston.

19. Lawson, B., \& Samson, D. (2001). Development innovation capability in organization: a dynamic capability approach. International Journal of Innovation Management, 5(3), 377-400.

20. Lee, Y.Y. (2012). Technology Education Development in Taiwan. Presented in 2012 educational forum for university President. Miaoli: Yuda Technology University.

21. Lin, K. W., \& Huang, K. P. (2012). Dynamic capability and its effects on firm performance. American Journal of Applied Sciences, 9(1), 107-110.

22. Lin, T. M. (2011), Technical and vocational education personnel training policy- Brief introduction of Technical 
and vocational education and recycling program , Quarterly Journal of Technological and Vocational Education, 1 (2) , 2-6.

23. Luo, Y. (2000). Dynamic capabilities in international expansion. Journal of World Business, 35(4), 355-378.

24. Ma, J., \& Todorovic, Z. (2011). Making universities relevant: market orientation as a dynamic capability within institutions of higher learning. Academy of Marketing Studies Journal, 15(2), 1-15.

25. Macher, J. T., \& Mowery, D. C. (2009). Measuring dynamic capabilities: practices and performance in semiconductor manufacturing. British Journal of Management, 20, S41-S62.

26. Ministry of Education. (2011). Technology Education Development in the Last Decade. Taipei: Ministry of Education.

27. Prange, C., \& Verdier, S. (2011). Dynamic capabilities, internationalization processes and performance. Journal of World Business, 46, 126-133.

28. Rebora, G., \& Turri, M. (2011). Critical factors in the use of evaluation in Italian universities. Higher Education: The International Journal of Higher Education and Educational Planning, 61(5), 531-544.

29. Salunke, S., Weerawardena, J., \& McColl-Kennedy, J. R. (2011). Towards a model of dynamic capabilities in innovation-based competitive strategy: insights from project-oriented service firms. Industrial Marketing Management, 40(8), 1251-1263.

30. Schreyögg, G., \& Kliesch-Eberl, M. (2007). How dynamic can organizational capabilities be? Towards a dual-process model of capability dynamization. Strategic Management Journal, 28(9), 913-933.

31. Teece, D. J. (2007). Explicating dynamic capabilities: The nature and micro-foundations of (sustainable) enterprise performance. Strategic Management Journal, 28(13), 1319-1350.

32. Tsao, T. Y. ( 2007 ). The prospects of technical and vocational school in Taiwan. School Administration, $52, .79-89$

33. Winter, S. G. (2003). Understanding dynamic capabilities. Strategic Management Journal, 24, 991-995.

34. Wu, C. H. (2007). On the Application of Grey Relational Analysis and RIDIT Analysis to Likert Scale Surveys. International Mathematical Forum, 2(14), 675-687.

35. Wu, C.S. (2011). The issues and trends of higher education reform in Taiwan. Chang-Gung Journal of Humanities and Social Sciences, 4(2), 241-280.

36. Wu, M.C., Ho, S. H., \& Tai, C. F. (2008). An analytical study on the academic performance of department heads in universities. Higher Education, 3(2), 33-62.

37. Wu, M.L. (2011). Quantitative Research and Thesis Writing. Taipei: Wunan Book Co.

38. Yan, T. Y. (2010). A study on the relationships between professional competitiveness and experiencing learning of university faculty members. Journal of Taichung University, 24(20, 89-111.

39. Zollo, M., \& Winter, S. G. (2002). Deliberate learning and the evolution of dynamic capabilities. Organization Science, 13(3), 339-351.

40. Zott, C. (2003). Dynamic capabilities and the emergence of intra-industry differential firm performance: insights from a simulation study. Strategic Management Journal, $24,97-125$.

Published by Atlantis Press

Copyright: the authors 